\title{
Synovial Fluid Enhances Proliferation and Migration in Canine Keratocytes
}

\author{
Seungji Lee*, Seong Mok Jeong**, Seul-gi Bae***, Young-sam Kwon* and Sungho Yun*1 \\ *Department of Veterinary Surgery, College of Veterinary Medicine, Kyungpook National University, Daegy 41566, Korea \\ **Department of Veterinary Surgery, College of Veterinary Medicine, Chungnam National University, Daejeon 34134, Korea \\ ***Department of Veterinary Internal Medicine, College of Veterinary Medicine, Kyungpook National University, Daegu 41566, Korea
}

(Received: May 26, 2020 / Revised: July 28, 2020 / Accepted: August 18, 2020)

\begin{abstract}
Synovial fluid (SF) contains various factors which may be helpful for corneal stromal healing, such as cytokines, growth factors, hyaluronic acid, and proteins. Therefore, the purpose of this study was to determine the effect of SF on proliferation and migration in canine keratocytes. In order to evaluate the degree of proliferation and migration, canine keratocytes were cultured in DMEM containing 1\%, 3\%, 5\%, or $10 \%$ SF. Real-time PCR was performed in a control group and the group treated with $5 \% \mathrm{SF}$, in order to measure the expression levels of factors associated with corneal wound healing. These factors included interleukin-1 $\alpha$ (IL-1 $\alpha$ ), hepatocyte growth factor (HGF), transforming growth factor- $\beta$ (TGF- $\beta$ ), and $\alpha$-smooth muscle actin (SMA- $\alpha$ ). Proliferation assays demonstrated that proliferation was significantly enhanced in groups treated with greater than $3 \% \mathrm{SF}$, as compared with that of the control group. In addition, migration in all SF-treated groups was significantly increased as compared with migration in the control group, as measured by migration assays. mRNA expression of IL-1 $\alpha$ and HGF was significantly increased and mRNA expression of TGF- $\beta$ and SMA- $\alpha$ was significantly decreased in the cells treated with $5 \%$ SF. These findings suggest that SF may promote corneal wound healing.
\end{abstract}

Key words : canine keratocyte, corneal wound healing, migration, proliferation, synovial fluid.

\section{Introduction}

The cornea is the transparent structure that makes up the front part of the eye. The cornea plays an important role in protecting the contents of the eye and refracting light on to the retina. Due to its anatomical location, the cornea is exposed to external physical, chemical, and biological insults and is constantly undergoing the healing process (17). The stromal layer is the thickest part of the cornea and is crucial for maintaining corneal structure and function. Keratocytes in the stromal layer play important roles in corneal healing which is mediated by stimulation of numerous cytokines and growth factors $(1,11,16,26)$.

The first step in corneal wound healing is apoptosis of the keratocytes within the wound. Keratocytes adjacent to the wound are activated and migrate toward the gap created by the wound. Activated keratocytes, known as corneal fibroblasts, undergo proliferation in order to repopulate depleted keratocytes and produce extracellular matrix (ECM) to close the wound gap. For these reasons, proliferation and migration of keratocytes are essential aspects of corneal wound healing (17).

Synovial fluid (SF) is a plasma dialysate that contains various factors and is modified by components secreted from the joint tissue. Factors contributing the viscoelastic nature of SF include hyaluronic acid (HA) and fibronectin $(3,7)$. Due to the high levels of viscosity of HA, it remains longer on the

'Corresponding author.

E-mail : shyun@knu.ac.kr corneal surface, enhancing the delivery of growth factors and oxygen to corneal cells and promoting the stabilization of the tear film $(2,8)$. Fibronectin acts as temporary matrix during wound healing, resulting in easier migration of cells (11). Previous studies have found that SF contains numerous cytokines and growth factors, such as fibroblast growth factor (FGF), platelet-derived growth factor (PDGF), nerve growth factor, insulin-like growth factor (IGF), TGF- $\beta$, IL-1, and IL$6(4,9,12,13,15,19,22,27)$.

There are numerous studies that demonstrate the benefit of these lubricating factors and cytokines of SF in various cell types $(5,14,19,27)$. However, there are no studies that have investigated the effect of SF in canine keratocytes. Therefore, we aimed to assess the effects of SF on migration, proliferation, and cytokine levels in canine corneal keratocytes.

\section{Materials and Methods}

\section{Corneal tissue collection}

One healthy male Beagle dog (one-year-old, $10 \mathrm{~kg}$ ) that underwent humane euthanasia for a reason unrelated to this study was used. Prior to this study, the dog was determined to be free of ocular disease through ophthalmic examination. Immediately after routine enucleation, under sterile conditions, a full-thickness keratectomy sample was obtained using a sterile \#10 scalpel blade, taking care not to include the limbus. The excised corneal sample was preserved in sterile phosphate buffered saline (PBS). The Kyungpook National University Experimental Animal Ethical Committee approved the animal studies included in this work (2019-0160). All animal procedures were performed in accordance with the 
Association for Research in Vision and Ophthalmology Statement for the Use of Animals in Ophthalmic and Vision Research.

\section{Isolation of canine corneal keratocytes}

Cells were isolated from the tissue within a few hours after enucleation, according to methods described previously, with some modifications (23). For detachment of the endothelium, the whole layer of corneal tissue was treated with $0.05 \%$ Trypsin/EDTA-solution (Gibco, USA) and incubated at $37^{\circ} \mathrm{C}$ with $5 \% \mathrm{CO}_{2}$ for 5 minutes. The endothelial layer was scraped using sterile forceps and rinsed off from the cornea. The remaining tissue was cut into several small pieces and placed in a cell culture plate with the stromal layers facing down. The pieces were incubated for 10-15 minutes allowing them to adhere to the plate. Low glucose Dulbecco's modified eagle medium (DMEM) (Gibco, USA) supplemented with $10 \%$ fetal bovine serum (FBS) (Gibco, USA) and $100 \mathrm{IU} / \mathrm{ml}$ penicillin and $100 \mu \mathrm{g} / \mathrm{ml}$ streptomycin was used as a culture medium. After approximately 3-10 days, keratocytes began migrating from the explant. The tissue pieces were carefully removed using rat-toothed forceps and discarded. The cells were washed with sterile PBS and a $0.05 \%$ Trypsin/EDTAsolution was added. The plate was incubated for 5 minutes at $37^{\circ} \mathrm{C}$ with $5 \% \mathrm{CO}_{2}$. The same volume of DMEM containing $10 \% \mathrm{FBS}, 100 \mathrm{IU} / \mathrm{ml}$ penicillin, and $100 \mu \mathrm{g} / \mathrm{ml}$ streptomycin was added. After centrifugation for 5 minutes at 2,500 rpm at $24^{\circ} \mathrm{C}$, the keratocytes were seeded at $10,000-20,000 \mathrm{cells} / \mathrm{cm}^{2}$ and incubated in a humidified incubator with $5 \% \mathrm{CO}_{2}$ at $37^{\circ} \mathrm{C}$. The culture medium was replaced every 3-5 days. Keratocytes between passage 2 and 4 were used in all studies.

\section{Preparation of canine SF}

For the preparation of SF, ten healthy male Beagle dogs (five to eight years of age, $10-15 \mathrm{~kg}$ ) were used. All used joints of dogs were corfirmed to clinically healthy with physical and radiographic examinations. Arthrocentesis was performed aseptically from the stifle and shoulder joints. For each, a maximum of $0.5 \mathrm{ml}$ was collected using sterile needles $(21 \mathrm{G})$ and syringes. Joints that were suspected of having arthritis were not included and only the samples that extended more than $2.5 \mathrm{~cm}$ before breaking were used. Samples contaminated with hemolyzed blood were discarded.
The SF samples were centrifuged for 15 minutes at 3,000 $\mathrm{rpm}$ and the supernatant was used. All samples were collected into plane tube, stored at $4^{\circ} \mathrm{C}$, and used within a week.

\section{Proliferation assay}

Proliferation was assayed in a 96-well plate. Keratocytes were seeded at density of 5,000 cells per well and cultured in DMEM containing 10\% FBS and antibiotics (streptomycin/ penicillin) until confluent. After washing twice with PBS, the medium was replaced with serum free medium supplemented with either: no supplement, $1 \% \mathrm{SF}, 3 \% \mathrm{SF}, 5 \% \mathrm{SF}$, or $10 \%$ SF. All SF samples used in this assay were collected on the same day. After treatment for 24 hours, the proliferation assay was performed using the Cell Counting Kit-8 (CCK-8) (Dojindo Molecular Technologies, Inc., Gaithersburg, MD). Two hours after treatment with CCK-8, the final density of cells was measured using a microplate spectrophotometer (Epoch, Biotek instruments, USA) at $450 \mathrm{~nm}$. Using the same procedure, a second assay was performed at 96 hours after treatment.

\section{Migration assay}

Keratocytes $(500,000$ cells $/ \mathrm{ml})$ were seeded in a cultureinsert (Ibidi, GmbH, Martinsried, Germany) and grown until confluent in DMEM containing 10\% FBS and antibiotics (streptomycin/penicillin). The migration device was removed and a cell-free gap of approximately $500 \mu \mathrm{m}$ thickness was left between the two separate cell monolayers. The cells were washed with PBS and incubated for 24 hours in medium supplemented with the following: no supplement, $1 \% \mathrm{SF}, 3 \%$ $\mathrm{SF}, 5 \% \mathrm{SF}$, or $10 \% \mathrm{SF}$. To quantify the area of migration, phase contrast and fluorescent images of the cell-free gap before treatment and after 12 hours of treatment were captured using a digital camera coupled to an inverted microscope (CKX41, Olympus, Japan). The area of the gap and the migratory cells were calculated using the ImageJ software (National Institutes of Health, Maryland, USA).

\section{Real-time PCR analysis}

Keratocytes were seeded and grown until confluent in DMEM containing 10\% FBS and antibiotics (streptomycin/ penicillin). Cells were then incubated in serum free medium for 24 hours. After washing the cells with sterile PBS, one

Table 1. Sequences of PCR primers

\begin{tabular}{|c|c|c|c|}
\hline Gene & Primer & Sequence $\left(5^{\prime} \rightarrow 3^{\prime}\right)$ & Accession Number \\
\hline \multirow{2}{*}{ GAPDH } & Forward & GAT GCT GGT GCT GAG TAT GT & \\
\hline & Reverse & CAG AAG GAG CAG AGA TGA TGA C & \\
\hline SMA- $\alpha$ & Forward & AGA CAT CAG GGA GTG ATG GT & \multirow{2}{*}{ XM_534781.2 } \\
\hline ( $\alpha$-smooth muscle actin) & Reverse & GGT GAT GAT GCC GTG TTC TAT & \\
\hline \multirow{2}{*}{$\begin{array}{l}\text { IL-1 } \alpha \\
\text { (Interleukin-1 } \alpha)\end{array}$} & Forward & TCT CAA AGA CAT CCC AGC TTA C & \multirow{2}{*}{ NM_001003157 } \\
\hline & Reverse & ACT TAA ACT CAA CCG TCT CTT CT & \\
\hline \multirow{2}{*}{$\begin{array}{l}\text { HGF } \\
\text { (Hepatocyte growth factor) }\end{array}$} & Forward & AGG AGA TGA GAA ACG CAA ACA & \multirow{2}{*}{ NM_001002964 } \\
\hline & Reverse & GGC CTA GCA AGC TTC AGT AAT A & \\
\hline \multirow{2}{*}{$\begin{array}{l}\text { TGF- } \beta 1 \\
\text { (Transforming growth factor } \beta 1 \text { ) }\end{array}$} & Forward & CAT GTG GAG CTG TAC CAG AAA TA & \multirow{2}{*}{ NM_001003309 } \\
\hline & Reverse & CAC GAC TCC AGT GAC ATC AAA & \\
\hline
\end{tabular}


plate was maintained with serum free medium as a control group and the other plate was treated with 5\% SF. After 24
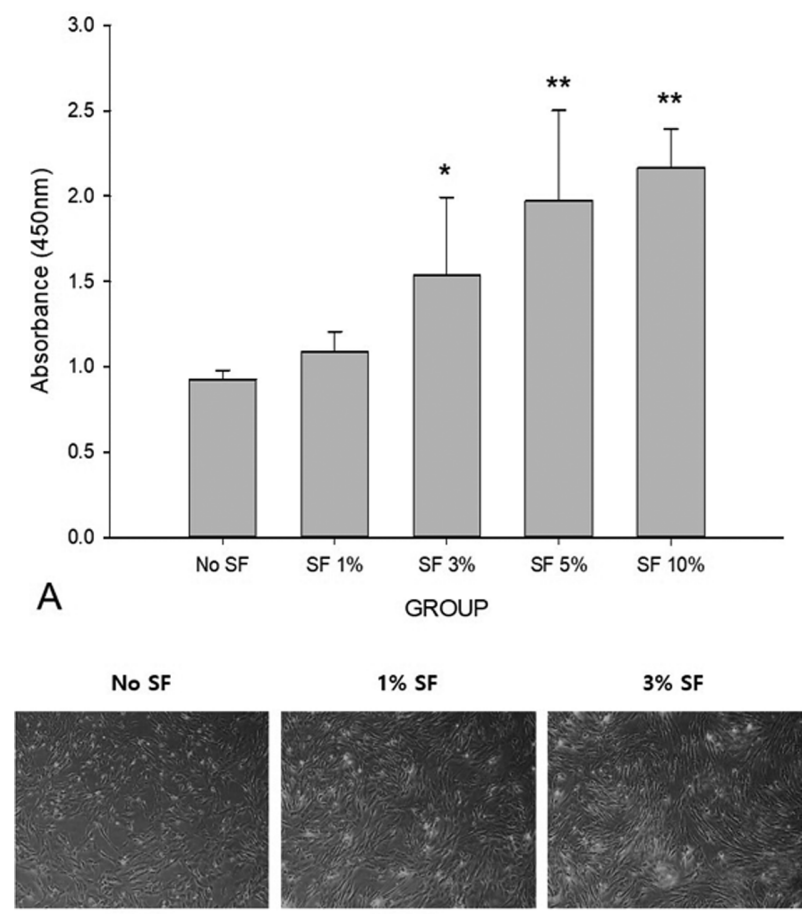

$5 \%$ SF

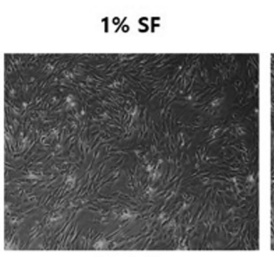

$10 \% \mathrm{SF}$
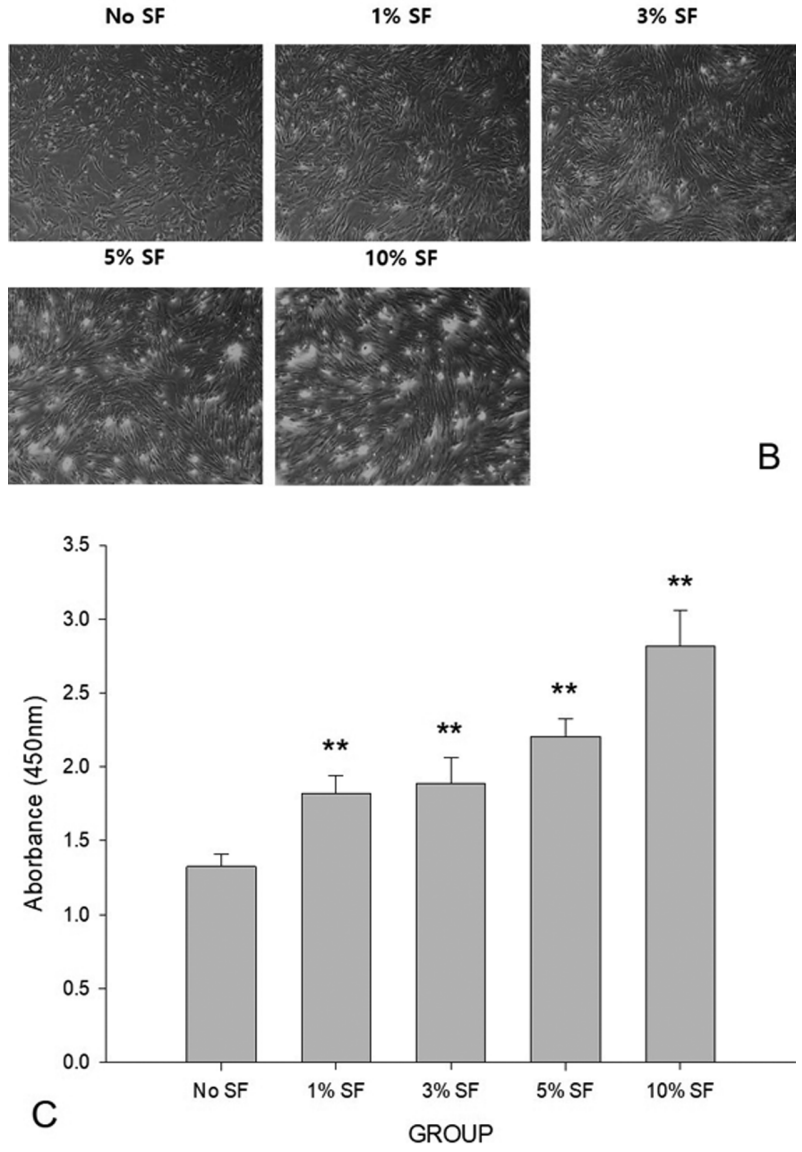

Fig 1. Proliferation of canine keratocytes. (A) The proliferation of canine corneal keratocytes treated with the following: serum free media, $1 \% \mathrm{SF}, 3 \% \mathrm{SF}, 5 \% \mathrm{SF}$, and $10 \% \mathrm{SF} 24$ hours after treatment. (B) Phase contrast microscopic images of canine corneal keratocytes treated with the following: serum free media, $1 \%$ SF, $3 \%$ SF, $5 \%$ SF, $10 \%$ SF, 96 hours after treatment (40× magnification). (C) The proliferation of canine corneal keratocytes treated with the following: serum free media, $1 \%$ SF, $3 \%$ SF, 5\% SF, and 10\% SF 96 hours after treatment. All data represent the mean $\pm \mathrm{SD}$. *: $P$-value $\leq 0.05$ compared with cells cultured without SF. ${ }^{* *}: P$-value $<0.001$ compared with cells cultured without SF. hours of treatment, the culture media was removed, the cells were washed with PBS, and harvested. The total RNA was extracted from the cell layers using the Trizol Reagent (Life technologies, USA). cDNA was synthesized from $1 \mu \mathrm{g}$ of total RNA from each sample using M-MuLV reverse transcriptase (Cosmogenetech, Seoul, Korea) and RNase inhibitor (Cosmogenetech, Seoul, Korea), according to the manufacturer's instructions. Real-time PCR was performed using the Bio-Rad CFX96 (Bio-Rad Laboratories, Inc., USA). A $20 \mu 1$ total volume mixture, included $10 \mu \mathrm{mol}$ of each primer, $5 \mu \mathrm{l}$ RT products (1:10 diluted), and $10 \mu \mathrm{l}$ Labopass SYBR Green Q master mix (Cosmogenetech, Seoul, Korea). After predenaturation for 3 minutes at $94^{\circ} \mathrm{C}$, the amplifications were performed for 40 cycles with the following steps: denaturation $\left(10\right.$ seconds, $\left.94^{\circ} \mathrm{C}\right)$, annealing $\left(10\right.$ seconds, $\left.60^{\circ} \mathrm{C}\right)$, extension $\left(20\right.$ seconds, $\left.62^{\circ} \mathrm{C}\right)$. The mixture including the IL- $1 \alpha$ primer was cycled 40 times at $94^{\circ} \mathrm{C}$ for 10 seconds, $58^{\circ} \mathrm{C}$ for 10 seconds, and $62^{\circ} \mathrm{C}$ for 20 seconds. At the termination of

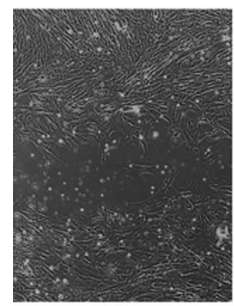

$5 \% \mathrm{SF}$
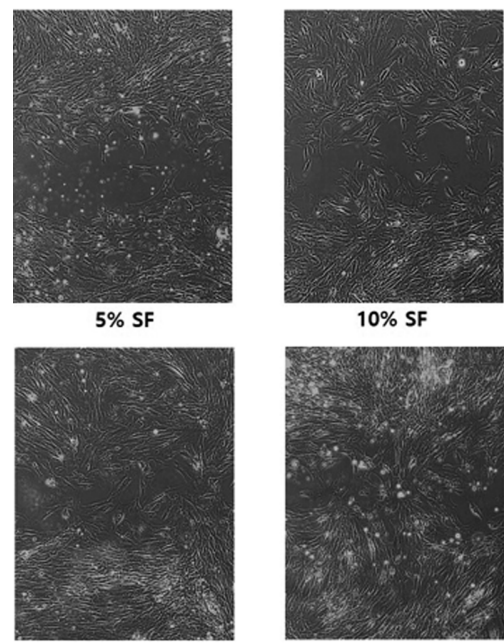

$10 \%$ SF

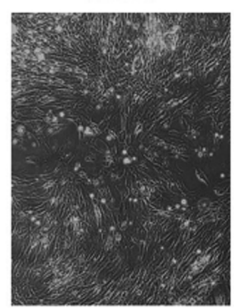

A

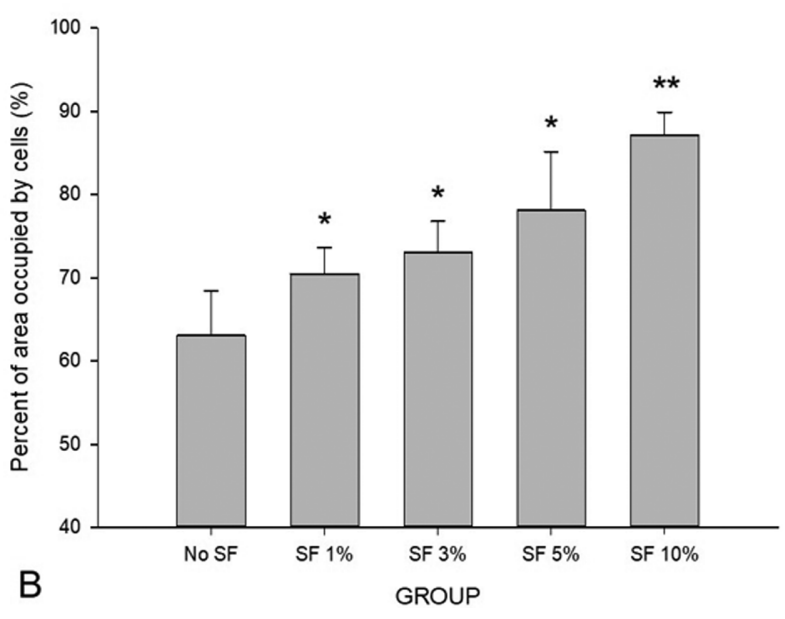

Fig 2. Migration of canine keratocytes. (A) Phase contrast microscope images of canine corneal keratocytes treated with the following: serum free media, $1 \% \mathrm{SF}, 3 \% \mathrm{SF}, 5 \% \mathrm{SF}$, and $10 \%$ SF 96 hours after treatment (100× magnification). (B) The area of migration of canine corneal keratocytes from the following groups: serum free media, $1 \% \mathrm{SF}, 3 \% \mathrm{SF}, 5 \% \mathrm{SF}$, and $10 \%$ SF 12 hours after treatment. All data represent mean \pm SD. *: $P$-value $\leq 0.05$ as compared with cells cultured without SF. **: $P$-value $<0.001$ compared with cells cultured without SF. 
the PCR, a melting curve generated and the samples were heated from $65^{\circ} \mathrm{C}$ to $95^{\circ} \mathrm{C}$ at a rate of $0.05^{\circ} \mathrm{C} / \mathrm{sec}$ elevation in order to confirm a single peak of fluorescence. Each sample was tested in triplicate. The relative expression of SMA- $\alpha$, IL- $1 \alpha$, HGF, and TGF- $\beta 1$ was calculated using the comparative threshold cycle $(\mathrm{Ct})$ with the CFX manager version 3.1. The GAPDH housekeeping gene was used as an internal control for normalization of RNA quantity. The primers are listed in Table 1.

\section{Statistical analysis}

For statistical analysis, parametric one-way analysis of variance followed by a Fisher test was performed using SigmaPlot Version 14 (Systat Software, Inc., USA). As it is difficult to assess the assumption of normality with the small amount of data available, a non-parametric Mann-Whitney analysis test was used to test group differences in the realtime PCR analysis (SPSS Statistics version 23, IBM SPSS Inc., USA). A value of $p \leq 0.05$ was considered statistically significant. A $p$-value $<0.001$ was considered highly significant. All data are presented as the mean \pm standard deviation.

\section{Results}

\section{Proliferation assay}

In keratocyte culture, SF treatment resulted in a significant increase in proliferation after 24 and 96 hours of treatment, as compared to the control group. Proliferation of canine corneal keratocytes was significantly increased in all of the treated groups, including the $3 \%, 5 \%$, and $10 \%$ SF groups at 24 hours, as compared to the control group, except in the $1 \%$ SF group (Fig 1A). Levels of proliferation in the $5 \%$ and $10 \%$ SF groups were highly statistically significant in comparison with the control group $(p<0.001)$. A second assay after 96 hours of treatment showed increased proliferation in the groups treated with $1 \%, 3 \%, 5 \%$, and $10 \%$ SF (Fig 1B and $1 \mathrm{C})$. All SF-treated groups in the second assay were statistically significant as compared with the control group ( $p<$ $0.001)$.

\section{Migration assay}

Compared with control group, migration in all SF-treated groups was significantly increased (Fig $2 \mathrm{~A}$ and $2 \mathrm{~B}$ ). In the
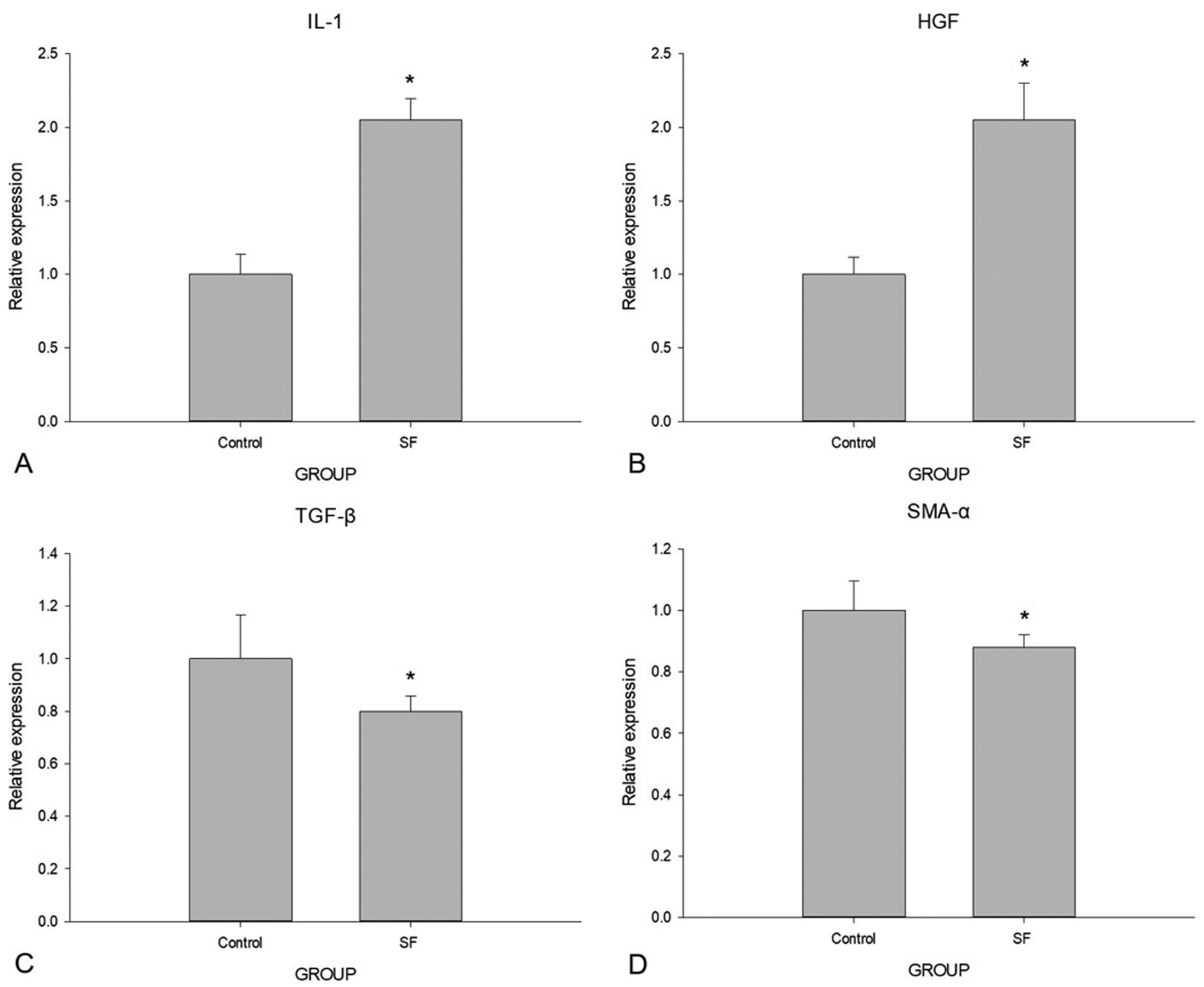

Fig 3. Relative mRNA expression of canine keratocytes. (A) Comparison of interleukin-1 $\alpha$ (IL-1 $\alpha$ ) mRNA expression levels between the control and SF group 24 hours after treatment. (B) The relative expression of hepatocyte growth factor (HGF) between the control and SF group 24 hours after treatment. (C) Comparison of transforming growth factor- $\beta 1$ (TGF- $\beta 1$ ) mRNA expression between the control and SF group 24 hours after treatment. (D) Relative mRNA expression of alpha smooth muscle actin (SMA- $\alpha$ ) in keratocytes cultured in serum free medium and medium with $5 \% \mathrm{SF}$. Data represent mean $\pm \mathrm{SD}$. *: $P$-value $\leq 0.05$. 
group treated with $10 \%$ SF there was an especially high rate of migration as compared with that of the control group.

\section{Real-time PCR analysis}

mRNA expression of factors associated with corneal wound healing, such as IL- $1 \alpha$, HGF, TGF- $\beta 1$, and SMA- $\alpha$, were examined. Relative expression of IL- $1 \alpha$ and HGF were significantly increased in the SF-treated group as compared with the control group (Fig 3A and 3B). mRNA expression of TGF- $\beta 1$ was statistically significantly decreased (Fig 3C) and SMA- $\alpha$ levels were statistically significantly decreased (Fig 3D), as compared with the control group.

\section{Discussion}

Keratocytes play an important role in corneal wound healing. Quiescent keratocytes adjacent to the wound edge are activated to become corneal fibroblasts, which have migratory and proliferative capacity. Corneal fibroblasts migrate into the wound to proliferate and replace depleted keratocytes, and also rapidly synthesize collagen and other components of the $\operatorname{ECM}(1,17)$. This healing process is mediated by numerous cytokines, growth factors, proteases, and ECM components and their receptors $(11,16,26)$.

SF consists of plasma dialysate and various factors secreted from joint tissues and contains numerous viscoelastic constituents, cytokines, and growth factors that may be involved in the proliferation and migration of cells $(2,9)$. There are several studies that have evaluated the effect of SF on various cells, including fibroblasts and osteoblasts $(5,14,19,27)$.

Previous studies have identified viscoelastic substances in $\mathrm{SF}$, including HA and fibronectin, which promote the migration of fibroblasts $(2,11)$. There are several studies that have identified the mitogenic effect of SF in various cells, including ligament fibroblasts and osteoblasts (19). In the present study, proliferation of keratocytes was significantly increased in the SF-treated group as compared with control group at 24 hours and 96 hours. In addition, the migration rate of keratocytes was increased in the SF group as compared to control group at 12 hours. These results suggest that SF benefits the corneal wound healing process through enhancing migration of corneal fibroblasts and promoting proliferation of keratocytes.

In the present study, the mRNA expression of IL- $1 \alpha$ in the SF-treated group was significantly increased as compared with the control group at 24 hours. IL-1 is primarily secreted from injured epithelium and plays various roles in corneal wound healing. As a pro-inflammatory cytokine, IL-1 mediates apoptosis of keratocytes within the wound in the early wound healing response. Apoptosis of keratocytes is an important process that occurs at the beginning of the healing process (26). IL-1 plays important roles in corneal remodeling in wound healing through activation of keratocytes and promoting the production of matrix metalloproteinases (MMPs) $(21,24)$. Previous studies have demonstrated that IL-1 has a mitogenic effect on keratocytes and promotes the migration of epithelial cells (12). This suggests that SF may help induce the wound healing process, through remodeling the wound by triggering apoptosis of injured cells and proliferation of new cells. However, because IL-1 mediates numerous inflammatory responses and pathological changes in various organs, further in vivo work is needed to further evaluate the effects of IL-1 induction by SF.

HGF is predominantly produced by stromal fibroblasts in response to corneal wounds and mediates epithelial cell function in a paracrine manner (16). In the cornea, HGF contributes to epithelization by accelerating proliferation and migration and inhibiting apoptosis of epithelial cells (18). In the present study, mRNA expression of HGF in corneal fibroblasts in the SF-treated group was significantly increased as compared to the control group at 24 hours. This result suggests that SF may contribute to corneal wound healing by enhancing proliferation of epithelial cells through HGF. However, as epithelial wound healing is mediated by numerous cytokines, additional work is needed to further identify the effects of SF in epithelial cells of the cornea.

Along with FGF-2 and PDGF, TGF- $\beta$ is a key cytokine involved in myofibroblast development and maintenance $(10,25)$. TGF- $\beta$ delays proliferation of keratocytes and promotes transformation into fibroblasts or myofibroblasts (6). For these reasons, TGF- $\beta$ plays important roles in corneal wound healing by increasing the migration and ECM production in cells. However, TGF- $\beta$ may cause fibrosis due to excessive maintenance of myofibroblasts after the wound healing process. Many studies have shown that attenuation of TGF- $\beta$ reduces fibrotic changes (20). In the present study, the mRNA expression of TGF- $\beta$ was not significantly different between the two groups. However, the TGF- $\beta$ that has an effect on keratocytes is predominantly secreted from epithelial cells. Further studies are needed to observe the effects of SF on corneal wound healing in vivo.

SMA- $\alpha$ is expressed by completely transformed myofibroblasts, and is considered a fibrotic marker. As myofibroblasts are highly contractile and have strong migration capacity, they play important roles in closing the wound gap. However, the haze associated with excessive and persistent myofibroblast activation after wound healing is considered a pathological response $(10,17,25)$. In the present study, despite the increased migration of keratocytes, the mRNA expression of SMA- $\alpha$ was not significantly increased in the SF group as compared to the control group at 24 hours. This result suggests that SF accelerates migration of keratocytes but does not increase numbers of myofibroblasts. However, as corneal haze is generally considered a long-term complication of a deep corneal wound, further long-term studies are needed to better assess this phenotype.

\section{Conclusion}

This study is the first, to our knowledge, that has assessed the response of canine keratocytes to SF treatment. Normal $\mathrm{SF}$ increased proliferation and migration without increases in mRNA expression of SMA- $\alpha$. SF increased mRNA expression of IL- $1 \alpha$ and HGF in canine corneal fibroblasts. These results suggest that normal SF may be helpful in corneal wound healing without affecting the generation of myofibroblasts. As this study was performed in simplified keratocytes culture for only a short time, long-term in vivo studies are 
necessary to further evaluate the effects of SF in corneal wound healing.

\section{References}

1. Ahmadi AJ, Jakobiec FA. Corneal wound healing: cytokines and extracellular matrix proteins. Int Ophthalmol Clin 2002; 42: 13-22.

2. Balazs EA. The physical properties of synovial fluid and the special role of hyaluronic acid. Disorders of the Knee 1974; 2: $61-74$.

3. Blewis ME, Nugent-Derfus GE, Schmidt TA, Schumacher BL, Sah RL. A model of synovial fluid lubricant composition in normal and injured joints. Eur Cell Mater 2007; 13: 26-39.

4. Fredj-Reygrobellet D, Plouet J, Delayre T, Baudouin C, Bourret F, Lapalus P. Effects of aFGF and bFGF on wound healing in rabbit corneas. Curr Eye Res 1987; 6: 1205-1209.

5. Fuchs TF, Petersen W, Vordemvenne T, Stange R, Raschke M, Paletta JR. Influence of synovial fluid on human osteoblasts: an in vitro study. Sci World J 2007; 18: 2012-2020.

6. Gallego-Muñoz P, Ibares-Frías L, Valsero-Blanco MC, Cantalapiedra-Rodriguez R, Merayo-Lloves J, Martínez-García MC. Effects of TGF $\beta 1$, PDGF-BB, and bFGF, on human corneal fibroblasts proliferation and differentiation during stromal repair. Cytokine 2017; 96: 94-101.

7. Gobezie R, Kho A, Krastins B, Sarracino DA, Thornhill TS, Chase M, Millett PJ, Lee DM. High abundance synovial fluid proteome: distinct profiles in health and osteoarthritis. Arthritis Res Ther 2007; 9: R36.

8. Gomes JA, Amankwah R, Powell-Richards A, Dua HS. Sodium hyaluronate(hyaluronic acid) promotes migration of human corneal epithelial cells in vitro. Br J Ophthalmol 2004; 88: 821-825.

9. Hamerman D, Taylor S, Kirschenbaum I, Klagsbrun M, Raines EW, Ross R, Thomas KA. Growth factors with heparin binding affinity in human synovial fluid. Proc Soc Exp Biol Med 1987; 186: 384-389.

10. Hinz B. Myofibroblasts. Exp Eye Res 2016; 142: 56-70.

11. Imanishi J, Kamiyama K, Iguchi I, Kita M, Sotozono C, Kinoshita S. Growth factors: importance in wound healing and maintenance of transparency of the cornea. Prog Retin Eye Res 2000; 19: 113-129.

12. Jester JV, Ho-Chang J. Modulation of cultured corneal keratocyte phenotype by growth factors/cytokines control in vitro contractility and extracellular matrix contraction. Exp Eye Res 2003; 77: 581-592.

13. Lambiase A, Manni L, Bonini S, Rama P, Micera A, Aloe L. Nerve growth factor promotes corneal healing: structural, biochemical, and molecular analyses of rat and human corneas. Invest Ophthalmol Vis Sci 2000; 41: 1063-1069.

14. Lee DA, Salih V, Stockton EF, Stanton JS, Bentley G. Effect of normal synovial fluid on the metabolism of articular chondrocytes in vitro. Clin Orthop Relat Res 1997; 342: 228238.

15. Lettesjö H, Nordström E, Ström H, Nilsson B, Glinghammar B, Dahlstedt L, Möller E. Synovial fluid cytokines in patients with rheumatoid arthritis or other arthritic lesions. Scand J Immunol 1998; 48: 286-292.

16. Lim M, Goldstein MH, Tuli S, Schultz GS. Growth factor, cytokine and protease interactions during corneal wound healing. Ocul Surf 2003; 1: 53-65.

17. Ljubimov AV, Saghizadeh M. Progress in corneal wound healing. Prog Retin Eye Res 2015; 49: 17-45.

18. Miyagi H, Thomasy SM, Russell P, Murphy CJ. The role of hepatocyte growth factor in corneal wound healing. Exp Eye Res 2018; 166: 49-55.

19. Schalkwijk J, Joosten LA, van den Berg WB, van Wyk JJ, van de Putte LB. Insulin-like growth factor stimulation of chondrocyte proteoglycan synthesis by human synovial fluid. Arthritis Rheum 1989; 32: 66-71.

20. Singh V, Barbosa FL, Torricelli AA, Santhiago MR, Wilson SE. Transforming growth factor $\beta$ and platelet-derived growth factor modulation of myofibroblast development from corneal fibroblasts in vitro. Exp Eye Res 2014; 120: 152-160.

21. Sivak JM, Fini ME. MMPs in the eye: emerging roles for matrix metalloproteinases in ocular physiology. Prog Retin Eye Res 2002; 21: 1-14.

22. Tandon A, Tovey JC, Sharma A, Gupta R, Mohan RR. Role of transforming growth factor Beta in corneal function, biology and pathology. Curr Mol Med 2010; 10: 565-578.

23. Werner A, Braun M, Kietzmann M. Isolation and cultivation of canine corneal cells for in vitro studies on the antiinflammatory effects of dexamethasone. Vet Ophthalmol 2008; 11: 67-74.

24. West-Mays JA, Sadow PM, Tobin TW, Strissel KJ, Cintron C, Fini ME. Repair phenotype in corneal fibroblasts is controlled by an interleukin-1 alpha autocrine feedback loop. Invest Ophthalmol Vis Sci 1997; 38: 1367-1379.

25. Wilson SE. Corneal myofibroblast biology and pathobiology: generation, persistence, and transparency. Exp Eye Res 2012; 99: 78-88.

26. Wilson SE, Mohan RR, Ambrósio R Jr, Hong J, Lee J. The corneal wound healing response: cytokine-mediated interaction of the epithelium, stroma, and inflammatory cells. Prog Retin Eye Res 2001; 20: 625-637.

27. Yang KG, Saris DB, Verbout AJ, Creemers LB, Dhert WJ. The effect of synovial fluid from injured knee joints on in vitro chondrogenesis. Tissue Eng 2006; 12: 2957-2964. 